Structure of mannose-specific snowdrop (Galanthus nivalis) lectin is representative of a new plant lectin family

Gerko Hester, Hanae Kaku, Irwin J. Goldstein and Christine Schubert Wright Nature Structural Biology, 2,472-479.

Figure 6 was misprinted, the correct version is shown below:
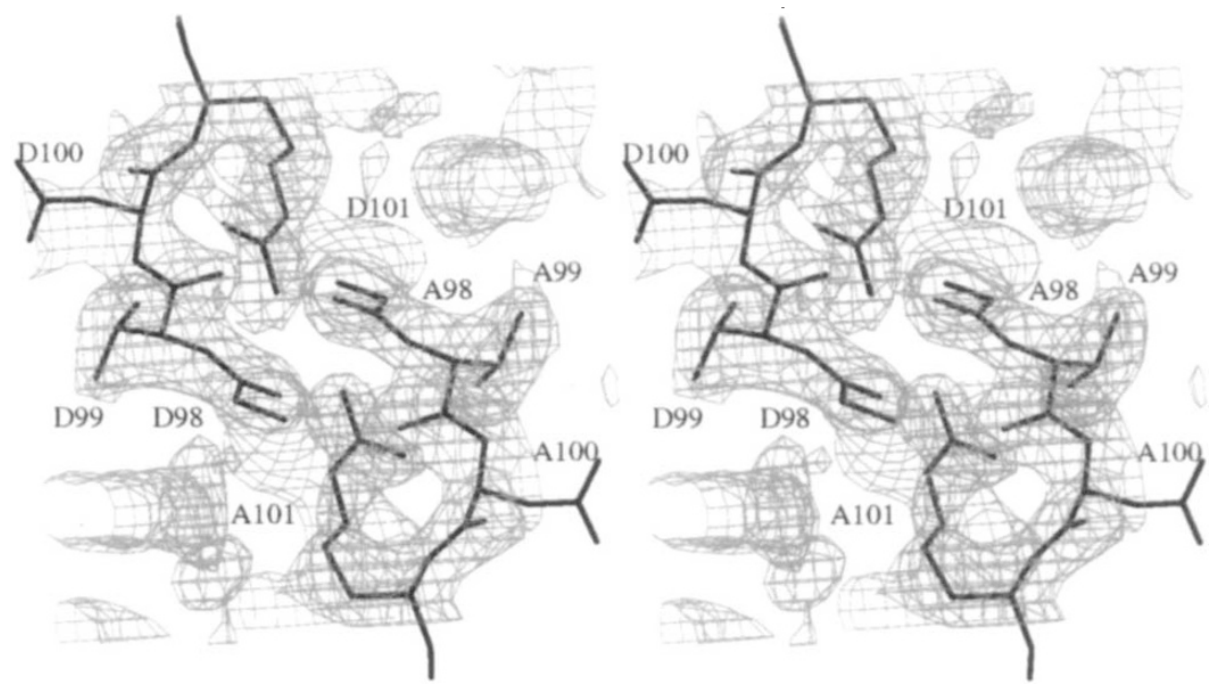

\title{
Alternating arginine-modulated substrate specificity in an engineered tyrosine aminotransferase
}

Vladimir N. Malashkevich, James J. Onuffer, Jack F. Kirsch and Johan N. Jansonius Nature Structural Biology 2, 548-553.

The following errors have been noted:

-Address should read: "Department of Structural Biology, Biozentrum, University of Basel, Klingelbergstrasse 70, $\mathrm{CH}-4056$ Basel, Switzerland".

-Page 548, second column, line nine should read: "All attempts to crystallize eTyrAT have failed so far. However, a hexamutant of eAspAt (V39L/K41Y/T47IIN69LI T109S/N297S) has been constructed which has 103-fold greater reactivity for aromatic amino acids than its parent AspAT, approaching that of eTyrAT, without losing any of its AspAT activity."

-Acknowledgements should read: "Supported by a Swiss National Science Foundation grant to J.N.J. and a NIH grant to J.F.K. J.J.O. was partially supported by a NIH Molecular Biophysics Training Grant."

-This note should have been added in proof: "The unpublished work from the JFK laboratory cited in the text is now in press in Protein Science". 